\title{
Perineal Tears Incidence and Risk Factors; A Four Years Experience in a Single Saudi Center
}

\author{
Al Hanouf Al Thaydi, Thamer Al Ghamdi, Ahmad Talal Chamsi* and Elham El Mardawi \\ Department of Obstetrics and Gynecology, Security Forces Hospital, Riyadh, Saudi Arabia
}

Received: 阱 April 06, 2018; Published: 畊 April 12, 2018

*Corresponding author: Ahmad Talal Chamsi, Department of Obstetrics and Gynecology, Security Forces Hospital, Riyadh, Saudi Arabia, Tel: +966 554070709; Email: ahmadchamsi@hotmail.com

\begin{abstract}
Background: Perineal trauma is a common event in obstetrics, affecting up to 90 percent of primiparous and is sometime associated with considerable post-natal morbidity and mortality [1]. These patients are at an increased risk of recurrent severe perineal lacerations in subsequent deliveries [2]. Many of these patients develop subsequent anal incontinence and sexual dysfunction despite an adequate primary sphincter repair [3].
\end{abstract}

Objectives: The aim of the study is to highlight the frequency and severity of perineal tears during vaginal delivery which leads to major physical, psychological and social problems.

Study Design and Methods: This retrospective cohort study analyzed all vaginal deliveries from January 2011 to December 2015 in Security Forces Hospital, Riyadh, Saudi Arabia. The Hospital has around 6000 deliveries per year. Data were extracted from dedicated database software for antenatal care through Hospital System (Medical Record Viewer MRV) and from Midwife Head Nurse daily record system. The data used were already available for the analysis for all patients as part of the clinical report of the Obstetrics and Gynecology Department of Security Forces Hospital.

Results: A total of 28325 patients were admitted for vaginal deliveries. Of them, 406 (1.4\%) patients sustained second, third or fourth degree perineal tears. Of the 406 patients, 285 (70.1\%) were primiparous and 121 (29.9\%) were multiparous. The mean age of the study population was 28.08 \pm 7.47, ranging between 17-42 years (Table 1). Of the total, 139 (32\%) delivered spontaneously, while 276 (68\%) delivered with the help of vacuum delivery. The primigravida were significantly associated with the frequency of severe lacerations $(\mathrm{p}<0.006)$. Perineal tears were not significantly associated with episiotomy $(\mathrm{p}<0.623)$. The occurrence of tears was in 313 (44.3\%) when birth weight $>4 \mathrm{Kg}(\mathrm{p}<0.001)$.

Conclusions: Perineal tears cause considerable post-natal morbidity. Identification of risk factors, vigilant monitoring and supervision by senior doctors during difficult deliveries and good perineal support is recommended for minimizing the risk of perineal trauma as well as morbidity.

Keywords: Perineal Tears; Severity; Risk Factors; Pregnancy; Obstetric Anal Sphincter Injury

\section{Introduction}

Perineal trauma is a common event in obstetrics, affecting up to 90 percent of primiparous and is sometime associated with considerable post-natal morbidity and mortality [1]. These patients are at an increased risk of recurrent severe perineal lacerations in subsequent deliveries [2]. Many of these patients develop subsequent anal incontinence and sexual dysfunction despite an adequate primary sphincter repair [3]. The most recognized classification of perineal tears by most obstetricians is the one adopted by Royal College of Obstetricians and Gynecologists (RCOG). They have classified perineal tears into four degrees; First degree: involving vaginal mucosa only; Second Degree: involving vaginal mucosa and perineal muscles; Third Degree involving anal sphincter; Fourth degree: involving the mucosa of the rectum. Third degree perineal is further subdivided into: $3 \mathrm{~A}$ if less than $50 \%$ of 
the external anal sphincter is involved, $3 \mathrm{~B}$ if more than $50 \%$ and $3 \mathrm{C}$ if the internal anal sphincter is involved [3]. Around 3-4\% of women after childbirth suffer from fecal incontinence which is because of occult anal sphincter injury that has either been missed or it has been wrongly classified as a second-degree tear $[4,5]$. Several risk factors such as nulliparity, prolonged labour, large babies, episiotomy, instrumental deliveries, induction of labour and the use of epidural analgesia have been reported in association with severe perineal lacerations [6]. Studies indicate that race is an independent risk factor for severe perineal lacerations after vaginal delivery, with Asian women at the highest risk [7]. Attention should be focused on the improvement of obstetric practice to minimize perineal trauma as anal sphincter damage following delivery is significantly associated with subsequent ano-rectal complaints [8]. The aim of the study is to highlight the frequency and severity of perineal tears during vaginal delivery which leads to major physical, psychological and social problems.

\section{Materials and Methods}

\section{Settings}

This retrospective cohort study analyzed all vaginal deliveries from January 2011 to December 2015 in Security Forces Hospital, Riyadh, Saudi Arabia. The Hospital has around 6000 deliveries per year. Data were extracted from dedicated database software for antenatal care through Hospital System (Medical Record Viewer MRV) and from Midwife Head Nurse daily record system. The data used were already available for the analysis for all patients as part of the clinical report of the Obstetrics and Gynecology Department of Security Forces Hospital.

\section{Ethical Approval}

The management of each pregnancy was not modified by the study, so it was considered exempt from IRB approval. Department Approval was obtained prior to data collection process.

\section{Subjects}

There was a total of 28325 deliveries from January 2011 till December 2015. 7322 deliveries (25.8\%) were cesarean deliveries and excluded from the study.

a. Inclusion criteria: Singleton pregnancy, cephalic presentation and vaginal delivery at term weeks of gestational age, patients who sustained second, third or fourth perineal tears. Exclusion Criteria: Any delivery not meeting the inclusion criteria and any delivery with missing data. The tear was categorized into four types: first-degree tear was defined as laceration limited to the superficial perineal skin or vaginal mucosa; second-degree tear was defined as laceration extending beyond fourchette, perineal skin and vaginal mucosa to perineal muscles and fascia, but not to the anal sphincter; third-degree tear included injury to fourchette, perineal skin, vaginal mucosa, muscles, and the anal sphincter; while the fourth-degree tear involved rectal mucosa as well. The study population included a total of 406 patients, 350 had second degree tears, 49 had third degree tears and 7 had fourth degree tears.

Interventions such as analgesia and use of oxytocin were performed according to specific clinical protocols for delivery care. Partograms were routinely used to monitor labor, woman's position, fetal head degree of flexion, plotting first and second stage times. Instrumental delivery was reserved for usual indications, such as arrested progression or fetal distress. All operative deliveries were carried out through vacuum extraction (in all cases Kiwi Omnicup according to manufacturer's instructions), without fundal pressure or forceps, by experienced and trained obstetricians. Great attention was paid after the delivery to assess the presence and the severity of obstetrical tears.

\section{Statistical Analysis}

Statistical analyses were performed using the SPSS (Statistical Package for the Social Sciences) version 17.0 (Chicago, IL, USA) for Windows. The effects of parity use of oxytocin, episiotomy, mode of delivery, Birth weight, and birth attendants on the degree of perineal tears were tested by Spearman's rho correlation (2-tailed). A $p$ value of less than or equal to 0.05 was considered significant.

\section{Results}

A total of 28325 patients were admitted for vaginal deliveries. Of them, 406 (1.4\%) patients sustained second, third or fourth degree perineal tears. Of the 406 patients, 285 (70.1\%) were primiparous and 121 (29.9\%) were multiparous. The mean age of the study population was $28.08 \pm 7.47$, ranging between $17-42$ years (Table 1). Of the total, 139 (32\%) delivered spontaneously, while 276 (68\%) delivered with the help of vacuum delivery. The primigravida were significantly associated with the frequency of severe lacerations $(\mathrm{p}<0.006)$. Perineal tears were not significantly associated with episiotomy $(\mathrm{p}<0.623)$. The occurrence of tears was in 313 (44.3\%) when birth weight $>4 \mathrm{Kg}(\mathrm{p}<0.001)$.

Table 1: Clinical Characteristics with degree of perineal tears $(n=406)$.

\begin{tabular}{|c|c|c|c|c|c|}
\hline Characteristics & $\begin{array}{c}\text { Total patients } \\
(n=406)\end{array}$ & $\begin{array}{l}\text { Second Degree Perianal } \\
\text { Tear }(n=350)=86 \%\end{array}$ & $\begin{array}{c}\text { Third Degree Perineal } \\
\text { Tear }(n=49)=12 \%\end{array}$ & $\begin{array}{c}\text { Fourth Degree Perineal } \\
\text { Tear }(n=7)=2 \%\end{array}$ & P-Value \\
\hline \multicolumn{6}{|l|}{ Parity } \\
\hline Primi-parous & 285 (70.1\%) & $61(21.3)$ & $105(36.8)$ & 119 (41.9) & $<0.001$ \\
\hline Multiparous & $121(29.9 \%)$ & $49(40.4)$ & $42(34.3)$ & $30(24.7)$ & $<0.005$ \\
\hline Episiotomy & & $216(53.2)$ & $111(27.4)$ & 79 (19.4) & $<0.623$ \\
\hline
\end{tabular}




\begin{tabular}{|c|c|c|c|c|c|}
\hline Vacuum (Kiwi ) Delivery & $276(68 \%)$ & $125(45.2)$ & $90(32.7)$ & $61(22.1)$ & $<0.002$ \\
\hline Birth Weight $>4 \mathrm{~kg}$ & $313(44.3)$ & $102(32.5)$ & $113(36.1)$ & $98(31.3)$ & $<0.001$ \\
\hline
\end{tabular}

\section{Discussion}

Our Study showed that the frequency of perineal tears was (1.4\%) which was comparable with other studies which showed the frequency to be ranging from $1.3 \%$ to $5.8 \%$ [9]. In our study nulliparous women were at higher risk of the tear than multiparous. The relative inelasticity of the perineum in nulliparous, which is reduced after one or more deliveries, might be responsible for this [10]. Haadem et al had the same results, and suggested that this might be due to increased pressure on the perineum or the inelastic vaginal tissue which might be responsible [11]. Episiotomy did not represent either a risk or a protective factor for perineal damage while Borgatta et al found a decreased risk of anal sphincter tear when mediolateral episiotomy was used in nulliparous women, but an increased risk when used in multiparous women [12]. Vacuum deliveries were associated with $32 \%$ of severe perineal tears in our study. Similar findings have been reported by other authors [13]. A reason for this difference might be the velocity of extraction, which is higher in vacuum delivery and may lead to more trauma. The current study indicates a positive association between severe perineal tears and birth weight over $4000 \mathrm{~g}$, same association was reported by Bek et al. [14]. All women sustaining perineal trauma should be carefully examined to assess the severity of damage to the perineum, vagina and rectum. The repair must be performed or directly supervised by a practitioner trained in the repair of third and fourth degree perineal tears [15-20].

\section{Conclusion}

Perineal tears cause considerable post-natal morbidity. Identification of risk factors, vigilant monitoring and supervision by senior doctors during difficult deliveries and good perineal support is recommended for minimizing the risk of perineal trauma as well as morbidity [21-25].

\section{Authors' Contributions}

Thamer Al Ghamdi and Alhanouf Al Thaydi drafted the manuscript. Ahmad Talal Chamsi and Elham El Mardawi contributed to study conception and study design. Ahmed Talal Chamsi and AlHanouf Al Thaydi contributed to literature review and data collection. Thamer Al Ghamdi and AlHanouf Al Thaydi contributed to data analysis and data presentation in tables and figures. All Authors reviewed manuscript for editorial and intellectual contents. All authors have read and approved the final draft of manuscript.

\section{References}

1. Kean L (2010) Perineal trauma. In: luesly DM, Baker PN (Eds.), Obstetrics and Gynaecology: An evidence based text for MRCOG $\left(2^{\text {nd }}\right.$ edn), Hodder Arnold, London, UK, p. 447-456.

2. Peleg D, Kennedy CM, Merrill D, Zlatnik FJ (1999) Risk of repetition of severe perineal laceration. Obstet Gynecol 93(6): 1021-1024.
3. Sultan AH, Kamm MA, Hudson CN, Bartram CI (1994) Third degree obstetric and sphincter tears: risk factors and outcome of primary repair. BMJ 308(6933): 887-891.

4. Sultan AH, Kamm MA, Hudson CN, Thomas JM, Bartram CI (1993) Analsphincter disruption during vaginal delivery. N Engl J Med 329(26): 1905-1911.

5. Woodman PJ, Graney DO (2002) Anatomy and physiology of female perineal body with relevance to obstetrical injury and repair. Clin Anat 15(5): 321-334.

6. Riskin-Mashiash S, O Brian Smith E, Wilkins IA (2002) Risk factors for severe perineal tear: can we do better? Am J Perinatol 19(5): 225-234.

7. Goldberg J, Hyslop T, Tolosa JE, Sultana C (2003) Racial differences in severe perineal lacerations after vaginal delivery. Am J Obstet Gynecol 188(4): 1063-1067.

8. DeLeeuw JW, Vierhout ME, Struijk PC, Hop WC, Wallenburg HC (2001) Anal sphincter damage after vaginal delivery: functional outcome and risk factors for fecal incontinence. Acta Obstet Gynecol Scand 80(9): 830-834.

9. Farooq S, Farook SM, Abbasi RM (2010) Pattern of perineal tears during vaginal delivery at a public sector University Hospital of Sindh. Pak J Med Sci 26(4): 856-859.

10. Moller Bek K, Laurberg S (1992) Intervention during labour: risk factors associated with complete tear of the anal sphincter. Acta Obstet Gynecol Scand 71(7): 520-524.

11. Haadem K, Ohrlander S, Lingman G (1988) Long-term ailments due to anal sphincter rupture caused by delivery-a hidden problem. Eur J Obstet Gynecol Repord Biol 27(1): 27-32.

12. Borgotta L, Piening S, Cohen WR (1989) Association of episiotomy and delivery position with deep perineal laceration during spontaneous delivery in nulliparous women. Am J Obstet Gynecol 160(2): 294-297.

13. Combs CA, Robertson PA, Laros RK Jr (1990) Risk factors for thirddegree and fourth-degree perineal lacerations in forceps and vacuum deliveries. Am J Obstet Gynecol 163(1 Pt 1): 100-104.

14. Bek KM, Laurberg S (1992) Risk of anal incontinence from subsequent vaginal delivery after a complete obstetric anal tear.Br J Obstet Gynae col 99(9): 724-726.

15. Green J, Sooho S (1989) Factors associated with rectal injury in spontaneous deliveries. Obstet Gynecol 73(5 Pt 1): 732-738.

16. Nager CW, Halliwell JP (2001) Episiotomy increases perineal laceration length in primiparous women. Am J Obstet Gynecol 185(2): 444-450.

17. Woolley RJ (1995) Benefits and risks of episiotomy: a review of the English-language literature since 1980 Part II. Obstet Gynecol Surv 50(11): 806-835.

18. Walsh CJ, Mooney EF, Upton GJ, Motson RW (1996) Incidence of third -degree perineal tears in labour and outcome after primary repair. Br J Surg 83(2): 218-221.

19. Shiono P, Klebanoff MA, Carey JC (1990) Midline episiotomies: more harm than good? Obstet Gynecol 75(5): 765-770.

20. Poen A, Felt Bersma RJ, Dekker GA, Deville W, Cuesta MA, et al. (1997) Third degree obstetric perineal tear: risk factors and the preventive role of mediolateral episiotomy. Br J Obstet Gynecol 104(5): 563-566.

21. Johanson RB, Heycock E, Carter J, Sultan AH, Walklate K, et al. (1999) Maternal and child health after assisted vaginal delivery: five year 
follow-up of a randomized controlled study comparing forceps and ventouse. Br J Obstet Gynecol 106(6): 544-549.

22. Anthony S, Buitendijk S, Zonderven KT, van Rijssel EJ, Verkerk PH (1994) Episiotomies and the occurrence of severe perineal lacerations. $\mathrm{Br}$ J Obstet Gynecol 101(12): 1064-1067.

23. Fynes M, O'HerilhyC (2001) The influence of mode of delivery on anal sphincter injury and fecal incontinence. Obstet Gynacol 3(3): 120-125.
24. Nelson R, Norton N, Cautley E, Furner S (1995) Community-based prevalence of anal incontinence. JAMA 274(7): 559-561.

25. Cheetham MJ, Malouf AJ, Kamm MA (2001) Fecal incontinence. Gastroentrol Clin North Am 30(1): 115-130.

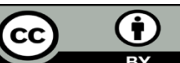

This work is licensed under Creative Commons Attribution 4.0 License

To Submit Your Article Click Here:

Submit Article

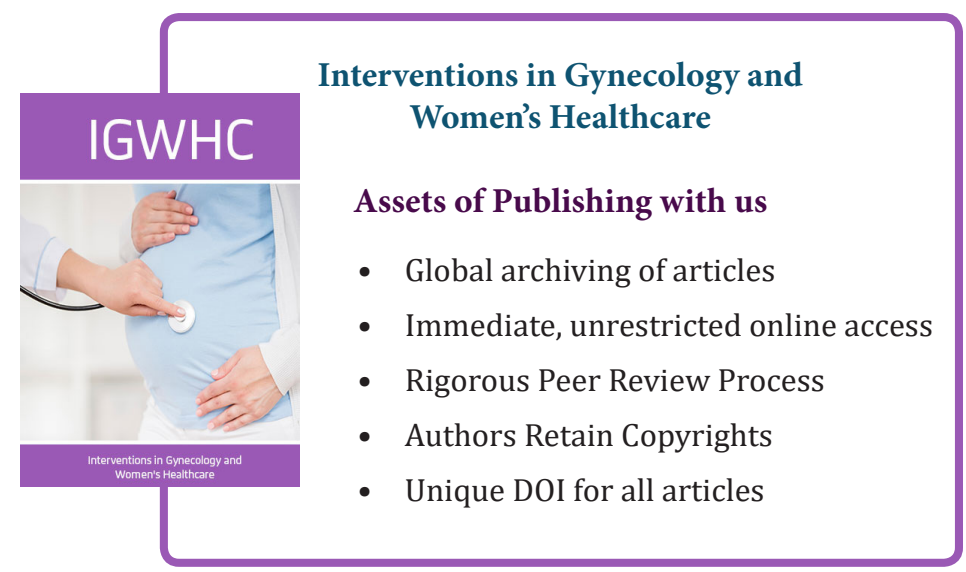

